\title{
Imprinting detection by extending a regression-based QTL analysis method
}

Olga Y. Gorlova $\cdot$ Lei Lei $\cdot$ Dakai Zhu

Shih-Feng Weng $\cdot$ Sanjay Shete $\cdot$ Yiqun Zhang

Wei-Dong Li $\cdot$ R. Arlen Price $\cdot$ Christopher I. Amos

Published online: 6 September 2007

(C) Springer-Verlag 2007

\section{Erratum to: Hum Genet}

DOI 10.1007/s00439-007-0387-2

The original version of this article unfortunately contained a mistake in the name of the next to the last author. It should read R. A. Price instead of Arlen Price R.

The online version of the original article can be found under doi:10.1007/s00439-007-0387-2.

O. Y. Gorlova $(\bowtie) \cdot$ L. Lei · D. Zhu · S.-F. Weng $\cdot$ S. Shete

Y. Zhang $\cdot$ C. I. Amos

Department of Epidemiology, MD Anderson Cancer Center,

University of Texas, Unit 1340, 1155 Pressler Street,

Houston, TX 77030, USA

e-mail: oygorlov@mdanderson.org

L. Lei

Amgen Inc., Thousand Oaks, USA

W.-D. Li • R. A. Price

Department of Psychiatry,

Center for Neurobiology and Behavior,

University of Pennsylvania, Philadelphia, PA USA 